\title{
Collective failure? Lessons from combining forecasts for the UK's referendum on EU membership
}

\author{
Stephen D. Fisher ${ }^{*}$ and Rosalind Shorrocks ${ }^{* *}$ \\ ${ }^{*}$ Corresponding author. University of Oxford \\ Address: Trinity College, Oxford, OX1 3BH \\ Email: stephen.fisher@trinity.ox.ac.uk \\ ${ }^{* *}$ University of Manchester \\ Email: rosalind.shorrocks@manchester.ac.uk
}

Accepted for publication by the Journal of Elections, Public Opinion and Parties, September 2017.

Keywords: election forecasting; combined forecast; EU referendum; British politics; Brexit

Acknowledgements: We are grateful to participants at the Elections, Public Opinion and Parties (EPOP) and PSA Political Methodology group conferences, and to three anonymous reviewers for helpful comments on earlier versions of the work. We are also grateful to Jonathan Jones for maintaining the ElectionsEtc.com website. 


\begin{abstract}
Research on election forecasting suggests there are benefits from combining different sources of information. This paper discusses the experience of a combined forecasting method that was developed for the UK's EU referendum in 2016. The sources included opinion polls, vote expectation surveys, prediction and betting markets, expert and volunteer forecasts, and various forecasting models based on polling and other kinds of data. Averages of sources within each of these categories all, in our final forecast, suggested Remain was more likely to win but with varying degrees of certainty. Combining them produced a forecast that beat some but not others. Opinion polls and citizen forecasts came closest to the true outcome. Betting and prediction market participants and volunteer forecasters were the most overconfident that the UK would vote Remain. This may have been because they were distrustful of the polls following the 2015 general election miss and had too strong an expectation of a late swing towards the status-quo similar to those in Scotland in 2014 and Quebec in 1995.
\end{abstract}

\title{
Introduction
}

The UK voted to leave the European Union in a referendum on 23rd June 2016. The result, 51.9\% for Leave to $48.1 \%$ Remain, was proclaimed as a shock by commentators. A large majority of the political elite were in favour of remaining in the EU. Many of them found it difficult to comprehend the idea that a majority of voters would be willing to take the substantial economic risk that leaving would entail. Leave supporters themselves acknowledged the risk and leaders of the Leave campaign did not expect to win even after the voting was over. The result genuinely was a shock to most people. But should it have been? 
There were many different indicators and attempts to forecast the outcome in advance. These included polls and models based on current and historical polling data; vote expectation surveys (aka citizen forecasts); prediction and betting markets; experts; volunteer forecasts; and models using economic and other indicators. Research on Germany and the US has shown that combining all such forecasts into one 'combined' forecast leads, on average, to greater accuracy, because such an approach uses all available information and should cancel out any errors systematic and random - present in each individual forecast (Graefe 2015). Following the success of such combined forecasts for Germany and the US elections, we developed a similar method to forecast the result of the EU referendum. The combined forecasts, together with the forecasts from each source, were published weekly on ElectionsEtc.com from mid-April 2016 until referendum day.

We constructed two such combined forecasts: one for the vote shares for each side, and one for the probability that Remain would win the referendum. All the publicly available and useable forecasts were classified according to the kind of forecast they represented: Betting markets, prediction markets, citizen forecasts, expert forecasts, volunteer forecasts, polls, poll-based models, and non-poll based models. Forecasts were averaged within each type with a straight arithmetic average. We refer to these as component forecasts. The combined forecast was simply the average across the components, i.e. the mean of the means for each type.

In our final forecast, all the components - and hence the combined forecast - predicted that Remain would win. However, at the same time, most components and the combined forecast showed consistent and considerable uncertainty about the likely outcome. The probability of a Leave victory was $33.5 \%$ in the final combined forecast. 
On this basis the outcome should not have come as a surprise. But it does raise questions as to why the forecasts - both component and combined - were almost uniformly in the wrong direction. We provide only tentative suggestions in response to such questions and related questions as to how and why the forecasts from different sources covaried over time. Further more thorough and focused research is needed on these issues but we hope our observations are helpful.

Our contribution, therefore, is not a definitive answer as to what went wrong with the various forecasts. Nor can a single referendum provide a sufficient test of the theory of combining forecasts. Our contribution is instead in providing an illustrative study of the theoretical and practical issues involved in combining diverse and sporadic sources for referendum forecasting. In so doing we feel that the experience helps shed further light on the behaviours of polls, markets, and other forecasts, and also on the trajectory of the EU referendum campaign itself.

In this paper we first discuss some of the previous literature on combining forecasts before outlining the method we developed for the Brexit referendum. We then discuss how the forecasts from the individual components and overall combined forecast changed over time, and evaluate some of the details of our approach. Issues about the extent to which markets, volunteers and citizens were following the polls are discussed in the conclusion together with some suggestions as to how referendum forecasting might be improved in future.

\section{Theory}

In the wake of the 2015 British general election polling miss, and several other major upsets internationally, such as the 2015 Israeli elections, there was considerable scepticism among the 
British public and commentators about the polls going into the 2016 Brexit referendum. There was correspondingly also a renewed appetite for considering other sources of information.

There has long been an academic debate about what sources and methods are best for election forecasting, for recent reviews see Fisher (forthcoming) and Murr (2017) and citations therein. Particularly prominent in this literature are questions about whether betting or (similarly) prediction markets are more informative than opinion polls. Wolfers and Zitzewitz (2004; 2006) argue that there is a strong economic theory as to why prediction markets should work well; people have incentives to acquire good information and the market should efficiently aggregate that information. On the other hand, sampling theory provides a theoretical basis for believing that opinion polls should do well, and Erikson and Wlezien (2012; 2008) argue that indeed polls tend to do better than election markets.

Whilst it is interesting and useful to understand the relative merits and defects of different forecasting methods, the advantages of combining different forecasts has also long been discussed. Granger and Bates (1969) argued that if you want to make the best forecast you should use all the information available, and not just restrict yourself to what you think is the best. This idea of combining different informative predictions has been expanded upon theoretically (Clemen 1989; Armstrong 2001; Graefe et al. 2014a). This literature tends to argue that averaging over different types of forecast can lead to greater accuracy over the long-run in a variety of settings and disciplines. Such combined forecasts have also been found to have high levels of accuracy for individual elections in the US (Lock and Gelman 2010; Montgomery, Hollenbach, and Ward 2012; Graefe et al. 2014b; Graefe 2017). 
This approach has not previously, to our knowledge, been used to forecast referendum outcomes. Armstrong (2001) argues that combining forecasts is particularly appropriate when you are uncertain about the situation and uncertain about which method is the most accurate. Prior to the Brexit referendum there was some academic literature on the dynamics of public opinion in referendum campaigns - including Le Duc (2003). That work informed the polls-based forecast of the EU referendum by Fisher and Renwick (2016a). It may well have been possible for someone to apply a more sophisticated dynamic Bayesian models that combined information, similar to Linzer (2013). But in our view there was not sufficient research based on referendum forecasting to generate strong priors as to how well different forecasting methods might work. Without strong evidence to prefer Bayesian averaging or to weight any one type of forecast over another, research suggests simple averaging is to be recommended over complex Bayesian averaging and other weighting methods (Graefe et al. 2015). For these reasons, we have applied a simple averaging method to our combined forecast similar to that applied by pollyvote.com in the US (Graefe et al. 2014b).

\section{Method}

Using a simple averaging procedure, we produced combined forecasts for both the probability of a Remain win, and for the vote shares both sides would receive. However, not all individual components provided both a probability and a vote share prediction; consequently, a slightly different set of sources was used for each. We tried to include all useable forecasts that were available, and we did not exclude any forecasts based on a judgement of quality. We did exclude a small number for other reasons, detailed below.

The following gives the details of the various components within the combined forecast. 


\section{Citizen forecasts}

Citizen forecasts come from the results of representative surveys of voters, asking them what they think the outcome will be. Such 'vote expectation surveys' have an excellent track record, arguably better than polls, prediction markets, quantitative models or expert judgment for US presidential elections (Graefe 2014). Proponents of these surveys for forecasting purposes explain this using Condorcet's jury theorem: if each individual in a group chooses the correct alternative with a probability that is greater than $50 \%$, then as the group increases in size the probability the group as a whole chooses correctly approaches 100\% (Murr 2016; Murr 2011). Evidence suggests that respondents are indeed more likely to predict the correct winner than not, even if this goes against their own preferences (e.g. Lewis-Beck \& Stegmaier, 2011).

In our forecast, the percentage who thought that Remain would win was taken as a collective estimate for the probability of a Remain win. The results of voter expectation surveys are listed at whatukthinks.org, and we used all of the wordings used by the various pollsters. For each pollster we took the average of the last two such polls within the previous three months, and then averaged across pollsters.

From the 9th June 2016 onwards, this component of the forecast allocated 50\% of respondents who said they didn’t know which side would win to the Remain percentage, and the other 50\% to the Leave percentage. The probability of a Remain win is then calculated as the percentage of all respondents in the poll who think Remain will win, rather than as a percentage of the respondents who offered an opinion as in forecasts calculated before this date. This was in order to more accurately capture the uncertainty felt by the respondents over the result. 
For the final forecast published on the $23^{\text {rd }}$ June, we restricted this component only to surveys with vote expectation questions conducted in the previous seven days, which in practice meant using one poll each from TNS, ORB, and Opinium. This was done out of a concern that the three-month window used for previous forecasts (initially set because of paucity of data) was overly wide and did not properly measure any movement in the opinions of respondents.

From the $14^{\text {th }}$ June 2016, we included within our combined forecast for the vote shares a poll from ORB which asked respondents to say what proportion of people they think will vote to Remain, and what proportion they think will vote to Leave. ${ }^{1}$

\section{Expert forecasts}

Expert forecasts are predictions by individuals who have expertise in the field and who are therefore expected to be able to make accurate predictions based on past and present information. In this category, we included predictions of the vote shares given by guests on The Times Red Box podcast. These predictions were part of a broader Times Red Box sweepstake that was open to the public and for which the contributors could be identified (usually by Twitter handle). Since there were some contributors to the sweepstake that we knew were experts (whether academics, journalists, pollsters, campaigners or commentators), we re-classified their predictions as expert even if they were not guests for the podcast.

\footnotetext{
${ }^{1}$ A further such poll was also published by ORB on $19^{\text {th }}$ June, but was missed during our data collection. It predicted a $50.3 \%$ share of the vote for Remain, and a corresponding $49.7 \%$ of the vote for Leave, and was therefore more accurate than the previous poll. This would have changed our combined forecast share of the vote to $53.1 \%$, instead of 53.3\%, making little difference to the final forecast.
} 
From the 9th June onwards, predictions from the Political Studies Association (PSA) Expert Survey were included (Jennings and Fisher 2016). Invitations to this online survey were sent to PSA members. They are mainly academics, but there were also a small number of journalists and pollsters. For the vote shares, we took the average prediction from the Red Box sweepstake and the PSA Expert Survey, weighted by their respective sample sizes.

For the expert forecast of the probability of a Remain win we used only the PSA Expert Survey, which explicitly asked the respondents to assign a probability to Leave winning a majority in the referendum.

There were a few other published expert forecasts but they were not used here because they did not provide figures for either the share of the vote or the probability of one side winning. They overwhelmingly pointed to Remain winning.

\section{Volunteer forecasts}

In this category we included other forecasts from individuals which do not fit into the vote expectation survey category, but were also not from individuals who could be identified as experts. We used in this category Philip Tetlock's Good Judgement project (www.gjopen.com) which encourages people to forecast the outcomes of various social and political events and helps them learn and improve their forecasting skills. Tetlock claims that given some training, effort and practice, reasonably intelligent citizens can forecast better than experts, at least collectively (Tetlock and Gardner 2015). One of their forecasting challenges was the outcome of 
the referendum. This gave only a probability of Remain winning and no forecast for the vote shares.

In addition, we used the volunteered contributions to the Times Red Box sweepstake, excluding those re-classified as expert as discussed above. The proportion of these volunteered contributions giving predicted Remain shares above $50 \%$ was again taken to be the probability of a Remain vote. The median Remain vote share was used for the share forecast.

\section{Prediction markets}

These are websites which allow people to bet on the outcome directly with other participants by buying 'shares' in either outcome, with no bookmaker setting the odds, and receive a pay-out if the purchased outcome is the one which occurs. They are much lauded as a forecasting tool by many economists and business people because they draw on views from a wide range of people willing to risk their own money. For election forecasting they arguably have a better track record than polls, quantitative models and expert judgement because markets aggregate public information about an event in real time (Graefe, forthcoming)

For the referendum the prediction market websites only had markets for which side would win and not the share of the vote. We used data from predictit.org and hypermind.com. We also used spread-betting markets from sportingindex.com and ig.com, taking the mid-point of the spread as the predicted probability or vote share. Because of low trading rates we did not use ipredict.co.nz, even though it did have a prediction market for the referendum. 
For some forecasts, sportingindex.com was not included because the market was suspended during data collection. This applies to the forecasts published on the $10^{\text {th }}$ May, $18^{\text {th }}$ May, and $23^{\text {rd }}$ June.

\section{Betting markets}

These are traditional bookmakers, but the logic behind such forecasts are similar to that of prediction markets. Even though the odds are formally set by the bookmakers, with enough people betting they are primarily driven by what the punters are willing to accept. We averaged the implied probabilities of Remain across major bookmakers listed on oddschecker.com after correcting for the over-round (whereby the sum of the implied probabilities from the published odds is more than 100).

Bookies allow people to bet on the share of the vote within particular bands (e.g. 45-50\% Remain). To generate a combined vote share forecast we took the mid-points of the bands and weighted them by the (corrected) implied probabilities. For large bands that extend to 0 or 100 we did not use the mid-points but figures five points from the interior bound. For example, if the band was $75 \%$ to $100 \%$, we used $80 \%$ for the share calculation. Implied probabilities for these extreme bands are very small so the choice of mid-point made little difference to the calculations.

\section{Polls}

For the combined share of the vote forecast we used polling averages, which typically aim to correct for differences between pollsters and so should not fluctuate too much according to whether the most recent polls were online or by telephone, or from a particular company. We 
used the average of the polling averages that were published online by whatukthinks, Ben Stanley (Stanley 2016), Number Cruncher Politics, the FT, and ElectionsEtc. From the $19^{\text {th }}$ June two additional polling averages were used from the Economist and Britain Elects. What we calculated was therefore a poll of polls of polls. For want of an (agreed) ideal method of poll averaging, this approach at least has the virtue of being within the spirit of combining.

Since polling averages do not reflect the range of variance in the polls very well, we generated a pseudo probability for Remain winning from the proportion of polls that had Remain ahead. For this we took just the last two polls from each company-method combination within the preceding two months. So if a company published two online polls and two phone polls in the previous two months these were treated separately. Here we made no attempt to balance between online and telephone polls even though there were slightly fewer companies doing phone polls and they more clearly pointed more towards Remain, especially prior to a few weeks before the vote.

For the final forecast on the $23^{\text {rd }}$, we narrowed the window within which we took individual polls in order to generate the pseudo probability to only polls conducted within the previous 7 days. This was to make sure the final forecast captured the movements in the polls accurately.

\section{Poll-based forecasting models}

Polls are a snap shot of opinion at the time they are taken. The historical relationship between polls and referendum outcomes tells us something about the direction and extent of any likely change in opinion, as well as the level of uncertainty we can expect of the outcome. Many such models were used to forecast the outcome of the 2015 General Election (e.g. Fisher, 2015; Ford, Jennings, Pickup, \& Wlezien, 2016; Hanretty, Lauderdale, \& Vivyan, 2016). For the EU referendum, only two such models were available, from ElectionsEtc and Number Cruncher 
Politics. They both provided forecasts of this kind for the probability of Remain winning and vote shares. The first forecast on the $20^{\text {th }}$ April did not include share predictions from Number Cruncher Politics because these had not yet been published.

\section{Non-poll based models}

We identified a number of miscellaneous other forecasting models for the EU referendum, all of which happened to only provide forecasts of the vote shares for Remain and Leave rather than a probability of Remain.

A traditional approach to election forecasting is to use historical data to develop a statistical model based on factors that are expected to influence the vote. These factors are often referred to as the "fundamentals" and are often used to forecast especially the outcomes of US elections (Lauderdale and Linzer 2015; Linzer and Lewis-Beck 2015). There was only one example of this approach that we know of for the referendum, from Matt Qvortup (Qvortrup 2016a; Qvortrup 2016b). We used the latest estimate published on twitter, which was consistently around 52\% for the entire period. His model was based on GDP, inflation, and the length of time the government has been in office.

A further set of models were included for the forecasts from the 9th June onwards, all of which predicted relatively high vote shares for Remain. euro-correspondent.com used information on the vote share gained by the various parties in the 2015 General Election and estimates of the proportion of each parties' supporters that were likely to vote for Remain, resulting in a prediction of a $54.2 \%$ vote share for Remain. ukgeneralelection2020.blogspot used a similar method using the results of the 2015 General Election and the 2014 European Parliament 
elections, which yielded predictions for Remain of $57.9 \%$ and $60.1 \%$ respectively. Finally, we also included a model from dataiq.co.uk based on big data and social media, which predicted a $54 \%$ vote share for Remain.

\section{Results and Evaluation}

Table 1 shows the forecast shares of the vote and probability of a Remain win from the first forecast, published on $20^{\text {th }}$ April 2016, and the final forecast, published early on polling day, the $23^{\text {rd }}$ June (Fisher and Shorrocks 2016a; Fisher and Shorrocks 2016b). The table shows the forecasts from each individual component as well as the combined forecast. All of them are in the wrong direction. The first and last combined forecasts were remarkably similar masking different patterns of change for different components. The probability assigned to a Remain win increased for the betting markets, prediction markets, and (to a lesser extent) in the volunteer forecasts, but dropped in the citizen forecasts, polls, and poll-based models. The betting markets had the lowest probability for Remain in the first forecast but the highest in the last. The probabilities and share of the vote estimates from the polls and citizen forecasts improved slightly, from the second and third best components in the first forecast to first and second place in the final forecast. Had we reallocated the Don't Knows from the vote expectation surveys in our first forecast as we did in our later ones, the first citizen forecast would have been $61.8 \%$ instead of 64.3. This would have made citizen forecast probabilities the best of the components in both the first and last forecasts (but often beaten by the implied probabilities from the polls in between). More broadly, viewed as a contest between different forecasting methodologies, Table 1 suggests that markets did badly and vote intention and vote expectation polls did best, but in a context of them all being wrong. 
Table 1. First and last component and combined forecasts

\begin{tabular}{lclllll}
\hline & \multicolumn{3}{c}{$20^{\text {th }}$ April forecast } & \multicolumn{3}{c}{ 23 June forecast } \\
\hline & Remain \% & $\begin{array}{l}\text { Leave } \\
\%\end{array}$ & $\begin{array}{l}\text { Probability } \\
\text { of a Remain } \\
\text { win }\end{array}$ & Remain \% & $\begin{array}{l}\text { Leave } \\
\%\end{array}$ & $\begin{array}{l}\text { Probability } \\
\text { of a Remain } \\
\text { win }\end{array}$ \\
\hline $\begin{array}{l}\text { Betting markets } \\
\text { Prediction markets }\end{array}$ & 53.9 & 46.1 & 62.2 & 53.5 & 46.5 & 76.7 \\
Citizen forecasts & & & 65.4 & & & 73.4 \\
Expert forecasts & 56.0 & 44.0 & 64.3 & 52.0 & 48.0 & 55.2 \\
Volunteer forecasts & 54.6 & 45.5 & 71.2 & 54.1 & 44.9 & 62.0 \\
Polls & 51.4 & 48.6 & 63.0 & 50.6 & 46.0 & 74.0 \\
Poll based models & 54.0 & 46.0 & 74.7 & 52.5 & 47.5 & 68.5 \\
Non-poll based models & 52.0 & 48.0 & & 55.6 & 44.4 & \\
Combined forecast & $\mathbf{5 3 . 3}$ & $\mathbf{4 6 . 4}$ & $\mathbf{6 6 . 8}$ & $\mathbf{5 3 . 3}$ & $\mathbf{4 6 . 7}$ & $\mathbf{6 6 . 5}$ \\
\hline Actual & $\mathbf{4 8 . 1}$ & $\mathbf{5 1 . 9}$ & & $\mathbf{4 8 . 1}$ & $\mathbf{5 1 . 9}$ & \\
\hline
\end{tabular}

NB: The data collection for the forecast published on $23^{\text {rd }}$ June took place in the evening of the $22^{\text {nd }}$ June.

To help understand how the forecasts changed over time and how the patterns of change were related to each other, Figure 1 shows the forecast Remain shares over time while Figure 2 presents the probabilities of a Remain win. There were just eleven forecasts in total, reflecting a kind of compromise between those sources that changed only very slowly if at all, and those that were much more frequently moving, especially markets. This low number of observations limits our ability to comment to very broad patterns. More detailed analysis, particularly regarding polls and markets, is left to further research.

Figures $1 \& 2$. Individual and combined forecast share of the vote for Remain (left) and probability of a Remain win (right). 

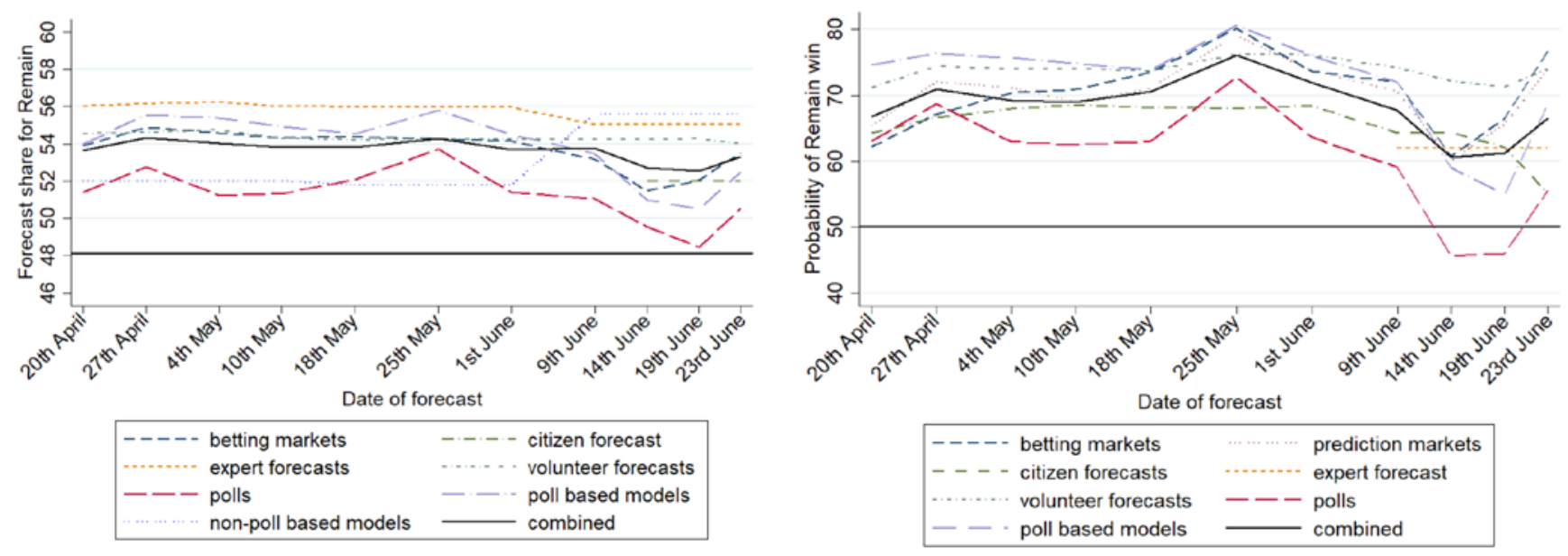

NB: Dates are date of publication. In some cases, data collection was conducted the evening before.

The horizontal lines show the actual vote share for Remain (48.1\%) (left) and 50\% probability for Remain (right)

Figures 1 and 2 further reinforce how almost entirely consistently wrong the forecasts were. Only the poll aggregations on the $14^{\text {th }}$ and $19^{\text {th }}$ June ever showed Leave ahead. Even they never showed Remain with as little as or less than the $48.1 \%$ of the vote that option eventually secured. Since all the errors were in the same direction, Figure 1 can in effect be read as a plot of the actual (absolute) error. It also follows from this that in our comments below higher Remain forecasts imply bigger errors.

The combined vote share forecasts pointed consistently to a Remain lead, and by a reasonable margin: the forecast hovered around $54 \%$ until a few weeks before the vote, when it dropped to around 52\% before rising again for the final forecast. However, the forecast probability of a Remain win showed that there was, in fact, considerable uncertainty about the outcome, especially closer to polling day. During the final 3 weeks, the combined forecast assigned a 30$40 \%$ probability to a Leave win. 
The polls in Figures 1 and 2 suggest three phases to the campaign period. Between 20th April and 25th May support for Remain was steady and perhaps increasing slightly. It then dropped steadily following publication on 26th May of immigration statistics showing net migration into the UK up to 330,000 in 2015, including a joint record high EU-only figure of 184,000 (BBC News 2016b). Also on 27th May the Parliamentary Treasury committee accused both sides of using statistics misleadingly, including the Remain side's claim that households would be $£ 4,300$ a year worse off by 2030 after leaving compared with remaining (BBC News 2016a). These events marked the start of a period of campaigning and debating much more dominated by immigration as an issue and distrust of economic arguments. Both of these were to the advantage of Leave. Even though both sides were criticised for their use of statistics, this was more problematic for the Remain campaign as it was almost entirely dependent on their economic argument.

The steady downward slide in support for Remain stopped with the murder of Jo Cox MP on 16th June. It then appeared to rally in the final week. ${ }^{2}$ However, this was mainly due to methodological changes implemented on the part of some pollsters for their final polls (Curtice 2016). Moreover, it was our own methodological change, restricting the final forecast to only those polls conducted in the previous 7 days, which increased the probability of a Remain win indicated by the polls. If the final forecast had also used a 2-month window, the probability of a Remain win forecast from the polls would have been $42 \%$ instead of $55.6 \%$. Whilst this methodological change captured the fact that the polls very close to the vote were more favourable to Remain than in the previous weeks, it did also make a substantial difference to the

\footnotetext{
${ }^{2}$ Our forecast of 19th June included mainly polls conducted before the murder.
} 
forecast. However, the general decline in support for Remain in the polls from the end of May to election day was not related to any methodological changes on our part and probably reflected a genuine shift in public opinion.

How much then did the other forecast components follow the opinion polls? When inspecting Figures 1 and 2 we should not expect perfect correspondence with the pattern of change in the polls because of the way that our polling average reflected some relatively old polls. But conversely it is helpful to note that in the case of the markets (and to a large extent poll-based models) what we have recorded as contemporaneous actually reflect forecasts made after the polls. Other sources can only be expected to track the very broad pattern of change in the polls, perhaps on a lagged basis. Although respondents to vote-intention polls might themselves be swayed by published forecasts, we suspect that such mechanisms would account for very little of the change over time in poll averages.

There were instances in the campaign where markets reacted sharply to the publication of particular polls. For example, on 18th May sterling increased by 2 cents on the publication of a poll by Ipsos MORI for the Evening Standard showing Remain on 55\% and Leave on 37\% (Reuters 2016). But even though markets and other forecasts may have responded to individual polls rather than to our poll aggregations, there should still be some signs of temporal correlation between polls and other components in our forecasts.

Indeed, vote share forecasts from the betting markets and of course poll-based forecasting models showed statistically significant positive correlations with the polls across our twelve published forecasts. Similarly for probabilities; betting markets, prediction markets, volunteers, 
citizens and poll-based model forecasts are all positively correlated with the probabilities derived from the polls, although only three of these five correlations are statistically significant. In most cases the weakness or lack of correlation with the polls was due to either limited data or changes in the nature of the data becoming available, so where we can reasonably make an assessment it does seem that the other forecasting components were, very broadly, tracking the polls.

This is not to say, however, that they were tracking the polls at an appropriate level or to the right extent. For our first two forecasts the betting markets had a lower probability for Remain than the polls implied according to our method. But since our method made no allowances for how far away the referendum was, at this point the markets might rightly have been making reasonable allowances for future change.

From the beginning of May, with a couple of exceptions ${ }^{3}$ the polls consistently predicted the lowest share of the vote for Remain and the lowest probability of a Remain win. Even when the polls forecast a Leave win in mid-June, the other components did not. This perhaps reflected an expectation on the part of bettors and other forecasters, and the expectation built into the pollbased models (Fisher and Renwick 2016b; Singh 2016), that the option perceived as the status quo - Remain - would outperform its polling numbers. This may have been reinforced by vivid memories of status-quo reversion in the 2014 Scottish independence and 1995 Quebec referendums. A context of distrust in the polls, following their failure to foretell the Conservative 2015 general election victory, probably also weakened the extent to which bettors reflected polling results. This is shown in the striking increase in the probability of a Remain win from

\footnotetext{
3 The exceptions are the Qvortrup model for the share of the vote which beat the polls when the poll share went over $52 \%$ and two occasions when the citizen forecast probability was lower.
} 
betting and prediction markets, and to a lesser extent volunteer forecasters, over the last week of the campaign, resulting in them forecasting the lowest probabilities of Leave winning the referendum.

Volunteer, expert and citizen forecasts, and non-poll based models showed less movement over the period for various, mostly structural reasons. For some aspects of these components there was simply no new information to add from week to week. The citizen forecast of vote share and the expert probability forecast was only ever based on one source and so stable from the point it was introduced. The expert forecasts of vote shares received a structural break with the publication of the PSA expert survey leading to a single step change. Similarly, the non-poll based model forecast was based on just one stable model until new ones were published and introduced on 9th June, after which there were no further changes. The forecasts from the Times Red Box sweepstake, which informed the volunteer and expert share (but not probability) forecasts suffered from sluggishness because they accumulated individual forecasts and so old ones numerically overwhelmed the steady trickle of those made later on.

The one forecast that might reasonably have been expected to have shown more movement and a strong link with the opinion polls but did not was the volunteer forecast of the Remain probability. This was based on the Good Judgement Project forecasters and so was continuously updated. On this occasion, at least, their trained volunteers were not the expert-beating super forecasters that Philip Tetlock claims they are (Tetlock and Gardner 2015). Indeed the volunteer probability forecasts were consistently one of the worst and were only narrowly saved from being the worst in the final forecast by the betting markets. 
By contrast the probabilities we generated from the citizen forecasts were almost consistently among the best. The two forecasts where they were not were largely due to data being old. The probability of a Remain win from the vote expectation surveys gradually decreased throughout June, although in a way that showed less temporal correlation with the polls than the markets did. As a result, the citizen forecasts assigned the highest probability to a Leave win after the polls in the final forecast. This was partially due to our methodological change of reallocating the Don't Know responses equally between the Remain and Leave predictions from the forecast on the $9^{\text {th }}$ June onwards. This change tended to decrease the probability given to a Remain win. However, even without this methodological change, the decline would have been evident: if the method had remained consistent, the probability assigned to Remain from citizen forecasts would have fallen from $67.7 \%$ to $61.4 \%$ (instead of $64.3 \%$ to $55.2 \%$ ) from $9^{\text {th }}$ June to polling day, still leaving it narrowly the second-best forecast component after the polls. ${ }^{4}$

As one anonymous reviewer has pointed out, the citizen forecast probabilities might have been even better had we estimated the relationship between the proportion of respondents who believed that Remain would win $(r)$ and the probability $(p)$ they assigned to a Remain win. For the data from citizens $p$ is unknown, but the expert survey has both and it would be reasonable to assume a logistic function that goes through $r=p=0.5$. Using this approach would effectively acknowledge that $p$ should be greater than $r$ when $r>0.5$. This would have been more reasonable a priori and on this occasion it would have improved our citizen forecast probabilities by moving them closer to, albeit still the wrong side of, 0.5 .

\footnotetext{
${ }^{4}$ The citizen forecasts would have performed similarly if our final forecast had used the initial three-month window, rather than the one-week window, for the final forecast. Restricting the surveys to only those conducted in the week before the vote (including the reallocation of Don't Knows) decreased the probability of a Remain win from citizens from $59.8 \%$ to $55.2 \%$.
} 
A similar approach would also have improved upon our pseudo-probability from vote intention polls if we were to have thought of $r$ as a proportion of polls not respondents. A state-space model of the polls (as a reviewer suggested) would be another viable approach. But if the houseeffects from such a model were effectively abstracted and the uncertainty for the median pollster were used then that would have produced a much more confident forecast for Remain. For the purpose of forecasting, variation between pollsters should be considered an important component of the uncertainty, not a nuisance to be controlled for.

\section{Conclusion}

Had the various different kinds of forecast been on average right then our combined forecasting method would have been a great success. As it was, the experience had more of the flavour of garbage-in-garbage-out. Still, despite the failure of the forecasts overall, we feel it provided a useful public service. It was a reasonable summary of the various component forecasts and the website was a helpful port of call for seeing what different forecasts were individually and collectively suggesting. Most importantly, the combined forecast rightly showed that there was a substantial probability that the UK would vote to leave the EU.

We hope that this paper, despite representing a case study of just one referendum with forecasts tracked at relatively few time points, has still provided helpful information about the potential nature of relationships between the different component forecasts that increases our understanding of their respective behaviours. For instance, we can see how markets during the 
Brexit referendum were responsive to opinion polls in some ways but not others. Also, we feel that the experience suggests some ways in which forecasting referendums and elections may be improved.

The probability assigned to a Remain win from prediction and betting markets steadily diverged from that of the polls, especially in the last three weeks before the referendum vote. This suggests that although markets have been found to do better than polls in some cases, there are contexts in which they do worse. Some have argued that the betting markets in this case did not reflect the actual bets that were being placed because the bookmakers themselves did not appropriately drop the price of Leave when bets for this outcome were made, but collapsed the price of Remain unrealistically in response to bets for Remain (Tapper 2016). However, if this was occurring it would have to have been with all bookmakers, as in general the odds given from each individual bookmaker were very similar to each other, for both probabilities and vote shares. Furthermore, prediction markets behaved in a similar way to betting markets and in these cases there was no bookmaker to potentially manipulate the odds.

It is perhaps more plausible that participants in the markets discounted current information from the polls because they did not conform to expectations based on past experience - i.e. that there would be a shift towards either the ‘status quo’ or the least 'risky’ option when voters actually went to the polls. However, in this case perhaps these expectations were laid on shakier foundations than those for general elections because of doubts about the comparability of previous referendums in the UK or elsewhere. Fisher and Renwick argued during the campaign that when comparing referendums cross-nationally, assertions that voters swing towards the 
status-quo option or are risk-averse in the final vote, while true on average, are highly variable and often do not hold (Fisher and Renwick 2016a). Nuances in the assumptions about how voters behave in referendums do not receive media attention and so are not likely to influence bettors’ decisions. It seems more likely that punters had in mind high profile examples, such as Scotland 2014 and Quebec 1995, when the referendum folklore did hold true.

It is also important, as Gelman and Rothschild (2016) have argued, to acknowledge the possibility that previous polling failures, particularly the 2015 general election, may have led bettors to discount polls, fixate on markets and so update too slowly. If this was true in this referendum of betting and prediction markets it also appears to have been true of trained volunteer forecasters, but not apparently of citizens in general.

Citizen forecasts did relatively well. They were, by our measures, beaten by the vote intention polls, but our methods for deriving implied probabilities from each were hardly satisfactory. For the opinion polls the main drawback is that our pseudo-probability (relative frequency with which Leave and Remain were ahead) was insensitive to the time left available. For citizen forecasts we translated responses to categorical questions about which side was most likely to win based on the relative frequencies. But one of the things that the PSA expert survey shows very clearly is that this approach can be a very poor guide to the respondents' average estimated probabilities. A large majority of the experts, 87\%, thought that Remain were most likely to win, but the average probability they gave to that event was just $62 \%$. For this reason we think it would be much better if pollsters asked respondents directly about what they think the probabilities of different outcomes are rather than just which outcome is more likely. This seems 
even more relevant to general election outcomes for which various different outcomes are relevant, not just which party is the largest. Moreover, given the wealth of evidence (Graefe 2017; Murr 2017) now suggesting that vote expectation surveys may be at least one of the best election forecasting tools, more such survey questions should be commissioned. Despite citizen forecasting comfortably outperforming opinion polls at the 2015 British general election it was striking that only 23 vote expectation survey questions were published, compared with 120 vote intention questions, in this referendum.

Our caveats about comparing the pseudo-probabilities from the polls and citizen forecasts illustrate a more general problem. The calculation of the combined forecast was subject to many decisions and judgement calls, the appropriateness of which have not been empirically tested. This was especially the case when using polling data and vote expectation surveys, but also expert and volunteer surveys. Further research could usefully explore how best to treat, aggregate and combine all the different data sources. 


\section{References}

Armstrong, J Scott. 2001. “Combining Forecasts.” In Principles of Forecasting: A Handbook for Researchers and Practitioners, edited by J. Scott Armstrong, 417-39. Norwell: Kluwer Academic Publishing.

BBC News. 2016a. “EU Referendum Campaigns 'Misleading Voters.”” http://www.bbc.co.uk/news/uk-politics-eu-referendum-36397732.

—. 2016b. "Net Migration to UK Rises to 333,000 - Second Highest on Record.” http://www.bbc.co.uk/news/uk-politics-eu-referendum-36382199.

Clemen, Robert T. 1989. “Combining Forecasts: A Review and Annotated Bibliography.” International Journal of Forecasting 5: 559-83.

Curtice, John. 2016. “How Leave Won the Battle but Remain May Still Win the War.” http://whatukthinks.org/eu/how-leave-won-the-battle-but-remain-may-still-win-the-war/.

Erikson, Robert S., and Christopher Wlezien. 2008. “Are Political Markets Really Superior to Polls as Election Predictors?” Public Opinion Quarterly 72 (2): 190-215. doi:10.1093/poq/nfn010.

—. 2012. “Markets vs. Polls as Election Predictors: An Historical Assessment.” Electoral Studies 31 (3). Elsevier Ltd: 532-39. doi:10.1016/j.electstud.2012.04.008.

Fisher, Stephen D. 2015. "Predictable and Unpredictable Changes in Party Support: A Method for Long-Range Daily Election Forecasting from Opinion Polls.” Journal of Elections, Public Opinion and Parties 25 (2): 137-58. doi:10.1080/17457289.2014.952732. . Forthcoming. “Election Forecasting.” In The Routledge Handbook of Elections, Voting Behaviour and Public Opinion, edited by Justin Fisher, Ed Fieldhouse, Mark N Franklin, Rachel Gibson, Marta Cantijoch, and Christopher Wlezien. Abingdon: Routledge. 
Fisher, Stephen D., and Alan Renwick. 2016a. "Do People Tend to Vote against Change in Referendums?” https://electionsetc.com/2016/06/22/do-people-tend-to-vote-against-changein-referendums/.

—_. 2016b. "Historical Referendums and Polls Based Forecast." https://electionsetc.com/category/historical-polls-based-forecast/.

Fisher, Stephen D., and Rosalind Shorrocks. 2016a. “A Combined Forecast for the UK’s EU Membership Referendum.” https://electionsetc.com/2016/04/20/a-combined-forecast-forthe-uks-eu-membership-referendum/.

—. 2016b. "Final Combined EU Referendum Forecast." https://electionsetc.com/2016/06/23/final-combined-eu-referendum-forecast/.

Ford, Robert, Will Jennings, Mark Pickup, and Christopher Wlezien. 2016. “From Polls to Votes to Seats: Forecasting the 2015 British General Election.” Electoral Studies 41:244-49. doi:10.1016/j.electstud.2015.11.013.

Gelman, Andrew, and David Rothschild. 2016. “Something’s Odd About the Political Betting Markets.” http://www.slate.com/articles/news_and_politics/moneybox/2016/07/why_political_betting _markets_are_failing.html.

Graefe, Andreas. 2014. “Accuracy of Vote Expectation Surveys in Forecasting Elections.” Public Opinion Quarterly 78 (S1): 204-32. doi:10.1093/poq/nfu008.

—. 2015. "Accuracy Gains of Adding Vote Expectation Surveys to a Combined Forecast of US Presidential Election Outcomes.” Research \& Politics 2 (1): 1-5. doi:10.1177/2053168015570416.

—. 2017. "Political Markets." In The SAGE Handbook of Electoral Behavior, edited by Kai 
Arzheimer, Jocelyn Evans, and Michael S. Lewis-Beck, 861-82. London: Sage Publications.

Graefe, Andreas, J. Scott Armstrong, Randall J. Jones, and Alfred G. Cuzan. 2014a. “Combining Forecasts: An Application to Elections.” International Journal of Forecasting 30 (1): 4354. doi:10.1016/j.ijforecast.2013.02.005.

Graefe, Andreas, J. Scott Armstrong, Randall J Jones, and Alfred G. Cuzan. 2014b. “Accuracy of Combined Forecasts for the 2012 Presidential Elections: The PollyVote.” PS: Political Science \& Politics, no. April: 427-31. doi:10.1017/S1049096514000341.

Graefe, Andreas, Helmut Küchenhoff, Veronika Stierle, and Bernhard Riedl. 2015. “Limitations of Ensemble Bayesian Model Averaging for Forecasting Social Science Problems.” International Journal of Forecasting 31 (3): 943-51. doi:10.1016/j.ijforecast.2014.12.001.

Hanretty, Chris, Ben Lauderdale, and Nick Vivyan. 2016. “Combining National and Constituency Polling for Forecasting.” Electoral Studies 41: 239-43. doi:10.1016/j.electstud.2015.11.019.

Jennings, Will, and Stephen D. Fisher. 2016. "Expert Predictions of the 2016 EU Referendum.” Lauderdale, Benjamin E., and Drew A. Linzer. 2015. “Under-Performing, over-Performing, or Just Performing? The Limitations of Fundamentals-Based Presidential Election Forecasting.” International Journal of Forecasting 31 (3): 965-79. doi:10.1016/j.ijforecast.2015.03.002.

LeDuc, Lawrence. 2003. The Politics of Direct Democracy: Referendums in Global Perspective. Toronto: Toronto University Press.

Lewis-Beck, Michael S., and Mary Stegmaier. 2011. “Citizen Forecasting: Can UK Voters See the Future?” Electoral Studies 30 (2): 264-68. doi:10.1016/j.electstud.2010.09.012. 
Linzer, Drew A. 2013. "Dynamic Bayesian Forecasting of Presidential Elections in the States.” Journal of the American Statistical Association 108 (501): 124-34. doi:10.1080/01621459.2012.737735.

Linzer, Drew, and Michael S. Lewis-Beck. 2015. "Forecasting US Presidential Elections: New Approaches (an Introduction).” International Journal of Forecasting 31: 895-97. doi:10.1016/j.ijforecast.2015.03.004.

Lock, Kari, and Andrew Gelman. 2010. "Bayesian Combination of State Polls and Election Forecasts.” Political Analysis 18 (3): 337-48. doi:10.1093/pan/mpq002.

Montgomery, Jacob M, Florian M Hollenbach, and Michael D Ward. 2012. “Ensemble Predictions of the 2012 US Presidential Election.” PS: Political Science \& Politics 45 (4): 651-54. doi:10.1017/S1049096512000959.

Murr, Andreas E. 2011. “'Wisdom of Crowds'? A Decentralised Election Forecasting Model That Uses Citizens’ Local Expectations.” Electoral Studies 30 (4): 771-83. doi:10.1016/j.electstud.2011.07.005.

— 2016. "The Wisdom of Crowds: What Do Citizens Forecast for the 2015 British General Election?” Electoral Studies 41: 283-88. doi:10.1016/j.electstud.2015.11.018.

—. 2017. "Wisdom of Crowds." In The SAGE Handbook of Electoral Behaviour, edited by Kai Arzheimer, Jocelyn Evans, and Michael S. Lewis-Beck, 835-60. London: Sage. Qvortrup, Matt. 2016a. "Referendums on Membership and European Integration 1972 - 2015.” Political Quarterly 87 (1): 1-8.

—. 2016b. “The EU Referendum.” Political Insight 7 (1).

Reuters. 2016. “Sterling Soars after Brexit Poll gives ‘In’ strong Lead.”. http://www.reuters.com/article/britain-sterling-idUSL5N18F444. 
Singh, Matt. 2016. “UK EU Referendum.”. http://www.ncpolitics.uk/uk-eu-referendum/.

Stanley, Ben. 2016. “The Brexit Poll.” http://rpubs.com/Ben_Stanley/154831.

Tapper, Albert. 2016. “Researching British Attitudes towards EU Membership and the 'Wisdom of Crowds'.” http://alberttapper.blogspot.co.uk/2016/07/libor-mk2-were-betting-marketson-eu.html.

Tetlock, Philip, and Dan Gardner. 2015. Superforecasting: The Art \& Science of Prediction. London: Random House.

Wolfers, Justin, and Eric Zitzewitz. 2004. "Prediction Markets.” The Journal of Economic Perspectives 18 (2): 107-26. - 2006. "Interpreting Prediction Market Prices as Probabilities.”. http://www.nber.org/papers/w12200. 